\title{
The occurrence and treatment of hemophagocytic lymphohistiocytosis caused by multiple factors: a case report and literature review
}

\author{
Weibin Zhuo, Dan Hao, Yong Tong, Wei Wu, Shijie Bao, Kaikai Huang, Yu Ling, Huamin Zhu, \\ Zhiqiang Sun \\ Department of Hematology, Shenzhen Hospital, Southern Medical University, Shenzhen, China \\ Correspondence to: Zhiqiang Sun. Department of Hematology, Shenzhen Hospital, Southern Medical University, Shenzhen, China. \\ Email: zhqsun69@163.com.
}

\begin{abstract}
Hemophagocytic lymphohistiocytosis (HLH) is a high-fatality disease caused by hereditary or acquired immune dysfunction, and is characterized by pathological inflammatory response. Primary HLH (pHLH) has hereditary genetic defects, and secondary HLH (sHLH) is caused by a variety of underlying diseases. Here, we report the case of a patient with aggressive natural killer cell leukemia and HLH-related gene defects who achieved long-term survival after treatment. A 20-year-old man presented to our hospital with symptoms of fever and fatigue. Investigations revealed splenomegaly, cytopenia, hyperferritinemia, hypofibrinogenemia, elevated levels of soluble CD25 (sCD25), and hemophagocytosis in bone marrow. Bone marrow flow cytometry showed 23.4\% abnormal natural killer cells, the cells were CD2, CD7, CD16, CD94, NKG2A positive, met the diagnosis of aggressive NK-Cell leukemia. Investigation of the patient's pedigree revealed that mutations of pHLH-related genes (LYST and UNC13D) were inherited from his father and mother, but neither of the parents had the disease. The patient received hematopoietic stem-cell transplantation (HSCT), after which he achieved complete remission. As of 2020-10-19, the patient's survival has exceeded 3 years, and he has returned to his normal life. A variety of factors contribute to the onset of HLH, and this case gives greater insight into the etiology of HLH. Allogeneic HSCT is a key treatment for HLH patients with underlying genetic mutations.
\end{abstract}

Keywords: Hemophagocytic lymphohistiocytosis (HLH); aggressive NK-cell leukemia; hematopoietic stem-cell transplantation (HSCT)

Submitted Dec 29, 2020. Accepted for publication Mar 03, 2021.

doi: 10.21037/apm-21-68

View this article at: http://dx.doi.org/10.21037/apm-21-68

\section{Introduction}

Hemophagocytic lymphohistiocytosis $(\mathrm{HLH})$ is a highly fatal disease that is characterized by pathological inflammatory response $(1,2)$. HLH can be classified as primary HLH (pHLH), which is related to hereditary genetic defects, or secondary HLH (sHLH), which is caused by a variety of underlying diseases.

In recent years, research on HLH has gradually deepened to reveal a relationship between pHLH and sHLH. Increasingly, it has been shown that sHLH patients carry genetic alterations, but triggered by secondary factors.

Here, we report the case of a 20 -year-old male patient with aggressive natural killer cell leukemia (ANKL) complicated by mutations in LYST and UNC13D, which eventually led to the onset of HLH. After receiving hematopoietic stem-cell transplantation (HSCT), the patient achieved complete remission. Investigation of the patient's pedigree revealed that mutations of LYST and UNC13D were inherited from his parents, but neither parent had the disease. 
Table 1 Results of laboratory investigations

\begin{tabular}{lcc}
\hline Laboratory parameter & Result & Reference range \\
\hline LDH (U/L) & 892.2 & $0-248$ \\
ALT (U/L) & 61.2 & $9-50$ \\
AST (U/L) & 114.1 & $15-40$ \\
Ferritin (ng/mL) & 14,378 & $22-322$ \\
Triglyceride (mmol/L) & 2.10 & $0-1.7$ \\
Fibrinogen (g/L) & 1.08 & $1.8-3.5$ \\
IL-6 (pg/mL) & 6.4 & $0-5.9$ \\
IL-10 (pg/mL) & 93.8 & $0-9.1$ \\
sCD25 (pg/mL) & $3,429.89$ & $410-2,623$ \\
\hline
\end{tabular}

ALT, lactate dehydrogenase; AST, aspartate aminotransferase; IL, interleukin; LDH, lactate dehydrogenase; sCD25, soluble CD25.

We present the following article in accordance with the CARE reporting checklist (available at http://dx.doi. org/10.21037/apm-21-68).

\section{Case presentation}

In October 2017, a 20-year-old male was admitted to our hospital after experiencing high fever and fatigue for 2 weeks. Physical examination showed $3 \mathrm{~cm}$ below the spleen ribs. Routine blood tests showed leukopenia [white blood cell count (WBC) $1.96 \times 10^{9} / \mathrm{L}$ ], neutropenia [neutrophils (N) $0.83 \times 10^{9} / \mathrm{L}$ ], thrombocytopenia [platelet count (PLT) $\left.63 \times 10^{9} / \mathrm{L}\right]$, and anemia [hemoglobin $\left.(\mathrm{Hb}) 69 \mathrm{~g} / \mathrm{L}\right]$. Additionally, elevated levels of lactate dehydrogenase, liver enzymes, ferritin, and cytokines were observed, whereas the patient's fibrinogen levels were low. Normal triglyceride levels were also recorded (Table 1). The results of EBV-DNA, herpes virus, respiratory pathogen, and T-SPOT tests were all negative. Bone marrow biopsy showed active hyperplasia, $4 \%$ of unidentified cells, and obvious hemophagocytosis. Bone marrow flow cytometry revealed $23.4 \%$ abnormal natural killer (NK) cells. The cells were positive for CD2, CD7, CD16, CD94, and NKG2A, and negative for sCD3, cCD3, CD4, CD5, CD8, CD56, CD161, CD158a, CD158b, CD158e, and NKG2C (Figure 1). Multiplex polymerase chain reactionbased next generation sequencing detected mutations in LYST (c.368A>G), UNC13D (c.1189G>A), and CREBBP (c.1651C>A). Next-generation pedigree analysis showed that the patient had inherited the mutations from his parents (Figure 2).

On the basis of the patient's results, the following diagnosis was made: (I) ANKL (with CREBBP mutation); (II) primary hemophagocytic syndrome (with mutations in LYST and UND13D). The patient subsequently received 4 courses of EPOCH + PEG-Asp-based chemotherapy [etoposide $(100 \mathrm{mg} / \mathrm{d}$, days $1-3)$, dexamethasone $(10 \mathrm{mg} / \mathrm{d}$, days $1-5)$, vindesine (4 $\mathrm{mg} / \mathrm{d}$, day 1$)$, cyclophosphamide $(1.2 \mathrm{~g} / \mathrm{d}$, day 5$)$, liposomal doxorubicin $(40 \mathrm{mg} / \mathrm{d}$, day 1 ; $20 \mathrm{mg} / \mathrm{d}$, day 2), and pegaspargase (3,750 IU/d, day 6)], The treatment effect was evaluated as partial remission. On May 9, 2018, the patient was admitted to a laminar flow ward for unrelated donor HSCT. He underwent a conditioning regimen with total-body irradiation/ etoposide/cyclophosphamide (TBI/VP16/Cy), and received peripheral blood HSCT (total nucleated cells $13.9 \times 10^{8}, \mathrm{CD} 34+7.07 \times 10^{6}$ per $\mathrm{kg}$ recipient body weight) on May 14, 2018. The patient was also administered cyclosporine and mycophenolate mofetil as graft-versushost disease prophylaxis. The patient achieved neutrophil and platelet engraftment on days 9 and 11 after the treatment, respectively. His disease remission continued post-transplant, and no maintenance therapy was required. Almost 3 years after the follow-up transplant, the patient was still alive and had returned to university.

All procedures performed in studies involving human participants were in accordance with the ethical standards of the institutional and/or national research committee(s) and with the Helsinki Declaration (as revised in 2013). Written informed consent was obtained from the patient.

\section{Discussion}

$\mathrm{HLH}$ is a rare disease, but with the improvement of diagnosis and treatment, as well as an increased understanding of the disease, a rising number of cases are being diagnosed and treated. The first cases of HLH were reported in pediatric patients and were mostly primary. However, it has been found that HLH can occur at any age and has a variety of causes $(1,3,4)$. Haemophagocytic lymphohistiocytosis has traditionally been classified according to the cause of disease and is divided into primary (genetic) and secondary (reactive). In children, underlying genetic defects play a predominant part in the development of haemophagocytic lymphohistiocytosis. In adults, the three main groups of causative factors are external (infections, 

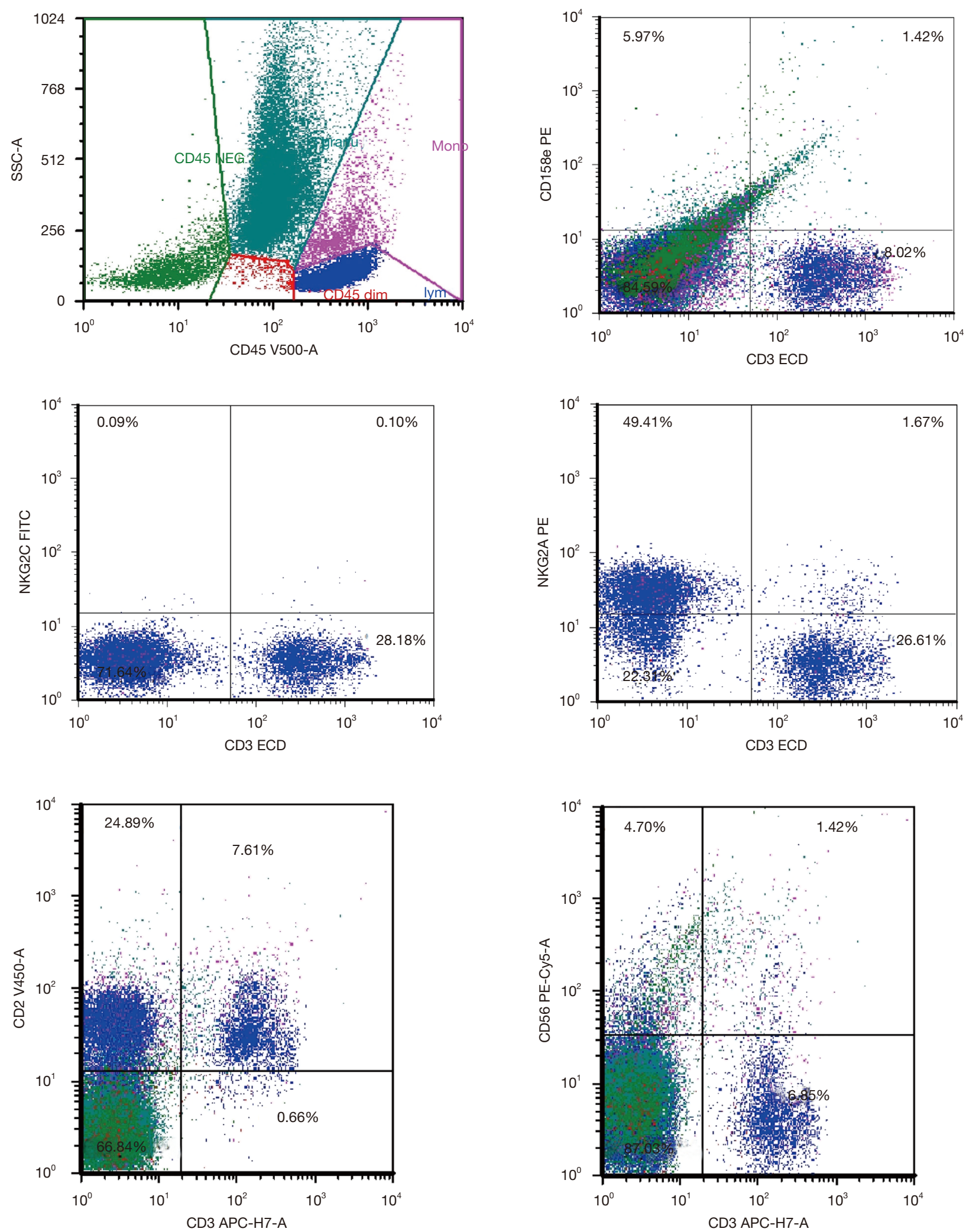

Figure 1 Bone marrow immunophenotyping. 


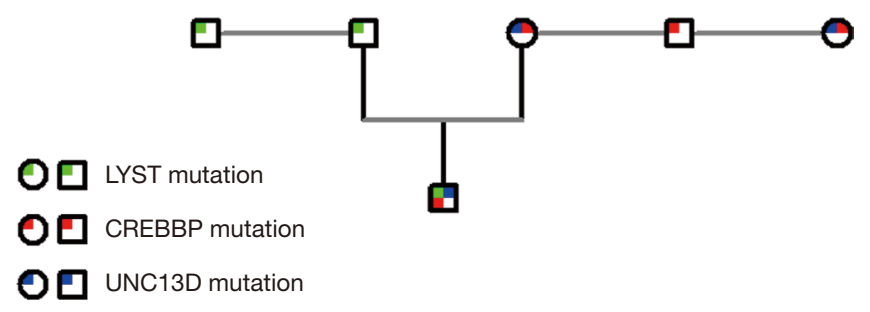

Figure 2 Pedigree analysis of the patient.

autoimmune and neoplasia); these diseases increase the risk of haemophagocytic lymphohistiocytosis. In adults, the three main groups of causative factors are external (infections, autoimmune and neoplasia); these diseases increase the risk of haemophagocytic lymphohistiocytosis. At least 12 genes are currently recognized as being related to HLH. With the in-depth understanding of the cause of the disease, especially in relation to genetic screening, some cases previously diagnosed as sHLH have been redefined as pHLH. Some scholars have even suggested that there is no boundary between pHLH and sHLH, and that the occurrence of HLH is more like a threshold disease (5-7). Various factors involved result in a cytokine storm basing of the existence of certain primary gene defects and triggering of tumors and infection $(8,9)$.

In the current case report, the patient was a 20 -year-old male with good health since childhood. The clinical manifestations of the patient were a persistent high fever, fatigue, splenomegaly, cytopenia, hyperferritinemia, hypofibrinogenemia, elevated levels of sCD25, and hemophagocytosis in bone marrow. At present, the diagnosis of HLH in adults should be based on the HLH2004 diagnostic criteria as well as clinical judgment and the patient's history (10). Furthermore, the combination of inflammatory cytokines (significantly increased levels of interferon- $\gamma(\mathrm{IFN}-\gamma)$ and IL-10, with a slightly increased IL-6 level) has high diagnostic accuracy for HLH $(11,12)$. According to the HLH-2004 standard, our patient met 7 of the 8 diagnostic criteria, and his clinical manifestations also supported HLH.

An interesting observation about this case is that immunophenotyping revealed that the patient's bone marrow was positive for CD2 and CD16, and negative for $\mathrm{sCD} 3$ and CD56, with no abnormal $\mathrm{B}$ cell or T cell expression. Although the patient's EBV-DNA test was negative, according to the World Health Organization 2016 criteria and his clinical manifestations, he met the diagnosis of EBV-negative aggressive NK-cell leukemia (with CREBBP mutation). Screening for HLH-related genes revealed the patient to have heterozygous mutations in LYST and UNC13D, which were inherited from both parents. However, neither of the patient's parents had developed the disease, indicating that the patient developed HLH due to mutations in the defective genes and with ANKL as the trigger. More than two heterozygous mutations HLH-associated genes have been described in some patients, and have a synergistic deleterious effect (13). In terms of treatment, considering the patient's diagnoses of ANKL and HLH, the EPOCH+PEG-Asp regimen was selected (14-16), and best supportive treatment was given. However, the patient's routine blood results did not return to normal. And due to defective genes, HSCT was considered to be the only suitable treatment option. Following unrelated donor HSCT, the patient's disease was alleviated. As of 2020-10-19, he had achieved long-term survival and had returned to his studies.

After reviewing the etiology of this case, we can see that various factors, including the presence of a tumor (ANKL) and pHLH-related genes (LYST and UNC13D), ultimately caused the occurrence of HLH. Although most cases of adult HLH are secondary, genetic defects have also been found in a part of older patients with the use of genetic testing. Although most cases of adult HLH are secondary, genetic defects have also been found in a part of older patients with the use of genetic testing.

There appears to be no distinct boundary between primary and secondary HLH. Instead, multiple factors combine, culminating in the final pathway to HLHcytokine storm. Studies of the mechanism underlying the occurrence of pHLH in children have been performed, but it is still unclear. In an animal model study, perforin double knockout (Prf1-/-) mice do not spontaneously develop HLH-like symptoms, but they manifest all of the features of HLH after infection with lymphocytic choriomeningitic virus (LCMV) (17). Another model found that the accumulation of monoallelic mutations increased the risk of developing HLH immunopathology after lymphocytic choriomeningitis virus infection (18). These findings suggest that in addition to innate immunodeficiency, external environmental factors, such as viral infection, are involved in triggering the development of the disease. Therefore the threshold for the development of HLH is when lymphocyte cytotoxicity can no longer maintain immune homeostasis.

Most patients with pHLH develop the disease before the age of 2. However, with the development of molecular 
diagnostic technology, it has been confirmed that pHLH can also affect older people. In fact, the oldest patient was 75 years old among the previous case reports (19). Clinicians should be aware of the possibility of pHLH in some adults, especially in patients with recurrent HLH, EBV infection, or unknown etiology. In this situation, pHLH-related tests should be considered, because which determines the choice of stem-cell transplantation for treatment. AlloSCT is necessary for patients with HLH mutations, but there are still some issues to be further discussed, such as the conditioning regimens and the selection of related donors (20-22).

\section{Acknowledgments}

Funding: None.

\section{Footnote}

Reporting Checklist: The authors have completed the CARE reporting checklist. Available at http://dx.doi.org/10.21037/ apm-21-68

Conflicts of Interest: All authors have completed the ICMJE uniform disclosure form (available at http://dx.doi. org/10.21037/apm-21-68). The authors have no conflicts of interest to declare.

Ethical Statement: The authors are accountable for all aspects of the work in ensuring that questions related to the accuracy or integrity of any part of the work are appropriately investigated and resolved. All procedures performed in studies involving human participants were in accordance with the ethical standards of the institutional and/or national research committee(s) and with the Helsinki Declaration (as revised in 2013). Written informed consent was obtained from the patient.

Open Access Statement: This is an Open Access article distributed in accordance with the Creative Commons Attribution-NonCommercial-NoDerivs 4.0 International License (CC BY-NC-ND 4.0), which permits the noncommercial replication and distribution of the article with the strict proviso that no changes or edits are made and the original work is properly cited (including links to both the formal publication through the relevant DOI and the license). See: https://creativecommons.org/licenses/by-nc-nd/4.0/.

\section{References}

1. Brisse E, Wouters CH, Matthys P. Hemophagocytic lymphohistiocytosis (HLH): A heterogeneous spectrum of cytokine-driven immune disorders. Cytokine Growth Factor Rev 2015;26:263-80.

2. Schulert GS, Canna SW. Convergent pathways of the hyperferritinemic syndromes. Int Immunol 2018;30:195-203.

3. Ramos-Casals M, Brito-Zerón P, López-Guillermo A, et al. Adult haemophagocytic syndrome. Lancet 2014;383:150316. Erratum in: Lancet 2014;383:1464.

4. Janka GE, Lehmberg K. Hemophagocytic syndromes--an update. Blood Rev 2014;28:135-42.

5. Jessen B, Maul-Pavicic A, Ufheil H, et al. Subtle differences in CTL cytotoxicity determine susceptibility to hemophagocytic lymphohistiocytosis in mice and humans with Chediak-Higashi syndrome. Blood 2011;118:4620-9.

6. de Saint Basile G, Sepulveda FE, et al. Cytotoxic granule secretion by lymphocytes and its link to immune homeostasis. F1000Res 2015;4:930.

7. Cetica V, Sieni E, Pende D, et al. Genetic predisposition to hemophagocytic lymphohistiocytosis: Report on 500 patients from the Italian registry. J Allergy Clin Immunol 2016;137:188-196.e4.

8. Schulert GS, Zhang M, Fall N, et al. Whole-Exome Sequencing Reveals Mutations in Genes Linked to Hemophagocytic Lymphohistiocytosis and Macrophage Activation Syndrome in Fatal Cases of H1N1 Influenza. J Infect Dis 2016;213:1180-8.

9. Clementi R, Locatelli F, Dupré L, et al. A proportion of patients with lymphoma may harbor mutations of the perforin gene. Blood 2005;105:4424-8.

10. La Rosée P, Horne A, Hines M, et al. Recommendations for the management of hemophagocytic lymphohistiocytosis in adults. Blood 2019;133:2465-77.

11. Tang $\mathrm{Y}, \mathrm{Xu} \mathrm{X}$, Song $\mathrm{H}$, et al. Early diagnostic and prognostic significance of a specific Th1/Th2 cytokine pattern in children with haemophagocytic syndrome. $\mathrm{Br} \mathrm{J}$ Haematol 2008;143:84-91.

12. Xu XJ, Tang YM, Song H, et al. Diagnostic accuracy of a specific cytokine pattern in hemophagocytic lymphohistiocytosis in children. J Pediatr 2012;160:98490.e1.

13. Zhang K, Chandrakasan S, Chapman H, et al. Synergistic defects of different molecules in the cytotoxic pathway lead to clinical familial hemophagocytic lymphohistiocytosis. 
Blood 2014;124:1331-4.

14. Jung KS, Cho SH, Kim SJ, et al. L-asparaginase-based regimens followed by allogeneic hematopoietic stem cell transplantation improve outcomes in aggressive natural killer cell leukemia. J Hematol Oncol 2016;9:41.

15. Wang J, Wang Y, Wu L, et al. PEG-aspargase and DEP regimen combination therapy for refractory Epstein-Barr virus-associated hemophagocytic lymphohistiocytosis. J Hematol Oncol 2016;9:84.

16. La Rosée P. Treatment of hemophagocytic lymphohistiocytosis in adults. Hematology. American Society of Hematology. Education Program 2015;2015:190-6.

17. Jordan MB, Hildeman D, Kappler J, et al. An animal model of hemophagocytic lymphohistiocytosis (HLH): CD8+ $\mathrm{T}$ cells and interferon gamma are essential for the disorder. Blood 2004;104:735-43.

18. Sepulveda FE, Garrigue A, Maschalidi S, et al.

Polygenic mutations in the cytotoxicity pathway increase

Cite this article as: Zhuo W, Hao D, Tong $\mathrm{Y}, \mathrm{Wu} W$, Bao S, Huang K, Ling Y, Zhu H, Sun Z. The occurrence and treatment of hemophagocytic lymphohistiocytosis caused by multiple factors: a case report and literature review. Ann Palliat Med 2021;10(3):3518-3523. doi: 10.21037/apm-21-68 susceptibility to develop HLH immunopathology in mice. Blood 2016;127:2113-21.

19. Zhang K, Jordan MB, Marsh RA, et al. Hypomorphic mutations in PRF1, MUNC13-4, and STXBP2 are associated with adult-onset familial HLH. Blood 2011;118:5794-8.

20. Naik S, Eckstein O, Sasa G, et al. Incorporation of thiotepa in a reduced intensity conditioning regimen may improve engraftment after transplant for HLH. Br J Haematol 2020;188:e84-e87.

21. Allen CE, Marsh R, Dawson P, et al. Reduced-intensity conditioning for hematopoietic cell transplant for HLH and primary immune deficiencies. Blood 2018;132:1438-51.

22. Hartz B, Marsh R, Rao K, et al. The minimum required level of donor chimerism in hereditary hemophagocytic lymphohistiocytosis. Blood 2016;127:3281-90.

(English Language Editor: J. Reynolds) 